\begin{tabular}{|c|l|}
\hline Title & Denaturation of Enzyme Protein by Freeze thawing \\
\hline Author(s) & HANA FUSA, Naofumi \\
\hline Citation & Cellular Injury and Resistance in Freezing Organisms : proceedings, 2, 33-50 \\
\hline Issue Date & 1967 \\
\hline Doc URL & http://hdl.handle.net/2115/20407 \\
\hline Type & bulletin (article) \\
\hline Note & $\begin{array}{l}\text { International Conference on Low Temperature Science. I. Conference on Physics of Snow and Ice, II. Conference on } \\
\text { Cryobiology. (A ugust, 14 19, 1966, Sapporo, Japan) }\end{array}$ \\
\hline File Information & \begin{tabular}{l} 
1_p33-50.pdf \\
\hline
\end{tabular} \\
\hline
\end{tabular}

Instructions for use 


\title{
Denaturation of Enzyme Protein by Freeze-thawing*
}

\author{
Naofumi Hanafusa \\ 花 房 尚更 \\ The Institute of Low Temperature Science \\ Hokkaido University, Sapporo, Japan
}

\begin{abstract}
Some physico-chemical parameters of frozen-thawed enzyme proteins were examined to investigate the mechanism of protein denaturation by freeze-thawing. The enzymatic activity and the conformational parameters of fibrous proteins, such as myosin $\mathrm{B}$, myosin $\mathrm{A}, \mathrm{H}$ - and L-meromyosin, decreased depending on the freezing temperature and the cooling rate. On the contrary, the conformational parameters of globular proteins, such as G-actin and catalase, did not change, in spite of the fact that the decrease of the enzymatic activity depends on the freezing temperature.

These results suggest that the freeze-thawing causes a partial unfolding of the helical structure in the fibrous proteins corresponding to the freezing conditions, but does not cause such a conformational change in the globular proteins. It might be said, therefore, that the molecular conformation is more stable against freeze-thawing in globular protein than in the fibrous protein.

The mechanism of the denaturation by freezing was discussed further in relation to the behavior of hydration water during the freezing process.
\end{abstract}

\section{Introduction}

Freeze-thawing or freeze-drying has been widely used for the preservation of various kinds of biological materials, in particular, for maintaining their biological activities over a long period of time.

It is known, however, that to a certain extent the biological activities suffer damage under certain conditions of freeze-thawing or freeze-drying.

Although many studies have been reported on the denaturation of protein caused by physical or chemical agents, the mechanism of the denaturation caused by freezethawing or freeze-drying has not been clarified as yet.

Recently, a number of studies were reported on the denaturation by freeze-thawing of enzyme protein, such as catalase (Ogawa, 1953; Shikama, 1961, 1963), myosin (Connell, 1960 ; Shikama, 1963; Hanafusa, 1962, 1964), and lactic dehydrogenase (Merkert, 1963; Kaplan, 1964). In these experiments changes in enzymatic activity were mainly examined, but no evidence on the conformational change of protein by freezing has been established.

The present experiment was carried out to elucidate the mechanism of denaturation on the basis of examination of changes in the molecular structure of protein. For this purpose, the following two problems were considered; one was to clarify the mechanism of an interaction between solvent water and protein molecules during the freezing process, i.e., to investigate the role that water plays on the structure and function of the protein

* Contribution No. 798 from the Institute of Low Temperature Science. 
from a biophysical point of view. The other was to establish fundamental evidence on the mechanism of the freezing injury of living organisms.

From such a stand point, the author first intended to examine the change in the physico-chemical parameters of fibrous and globular protein by freeze-thawing.

\section{Materials and Methods}

Materials. Myosin B was prepared from rabbit skeletal muscle according to SzentGyörgyi's method with some modification. The extract in $\mathrm{KCl}$ solution was precipitated by adjusting the $\mathrm{KCl}$ concentration to $0.3 \mathrm{M}$. The sediment was then resolved in $0.6 \mathrm{M}$ $\mathrm{KCl}$ solution. This purification was repeated twice.

The isolation of myosin A from rabbit skeletal muscle was made by following SzentGyörgyi's method as modified by Mommert, from which myosin B was removed by ultracentrifugation at 15000 r.p.m. in an ionic strength of 0.28 of $\mathrm{KCl}$ solution. The sediment was then resolved in a $0.5 \mathrm{M} \mathrm{KCl}$ solution. This purification procedure was repeated three times.

$\mathrm{H}$ - and L-meromyosin, prepared from myosin $\mathrm{A}$ by trypsin digestion, were purified according to Szent-Györgyi's method. They were stored as aqueous and $0.5 \mathrm{M} \mathrm{KCl}$ solutions, respectively.

G-actin was prepared from acetone dried muscle powder, from which myosin A was removed, by Straub's method. This was stored as an aqueous solution.

Catalase was obtained from beef liver according to Kitagawa and Shirakawa's method. Recrystallization procedures for purification were repeated three times. The final product was resolved in a $0.075 \mathrm{M}$ phosphate buffer solution at $\mathrm{pH} 7.5$.

All specimens, stored at $0^{\circ} \mathrm{C}$, were used for the experiments within two weeks after extraction.

Methods. The viscosity of the specimen was measured at $26^{\circ} \mathrm{C}$ by the use of an Ostwald type or Ubbelohde type viscosimeter.

Optical rotatory dispersion was measured with Rudolph Model $200 \mathrm{~S}$ photometric spectropolarimeter at $20^{\circ} \mathrm{C}$. The concentration of the specimen was between 0.8 and $1 \%$, and length of light path of the cell was $10 \mathrm{~cm}$. Moffit-Yang's equation was used to determine the parameter of helix contents of protein $b_{0}$ and $a_{0}$,

$$
[M]=\frac{3}{n^{2}+2} \frac{M_{0}}{100}[\alpha]=\frac{a_{0} \lambda_{0}^{2}}{\lambda^{2}-\lambda_{0}^{2}}+\frac{b_{0} \lambda_{0}^{4}}{\left(\lambda^{2}-\lambda_{0}^{2}\right)^{2}}
$$

where $[M]$ is the mean residue rotation at any wave length corrected for the refractive index $(n)$ of the solvents, $\lambda_{0}$ is the absorption wave length associated with the rotation (assumed to be $212 \mathrm{~m} \mu$ ), and $M_{0}$ is the average molecular weight per residue (Moffit and Yang, 1956).

Difference spectra were measured with a Cary Model 14 or Shimadzu Model 5 V$50 \mathrm{~A}$ automatic recording spectrophotometer and a Hitachi-Perkin Elmer Model 139 spectrophotometer using $1 \mathrm{~cm}$ quartz-cells.

Ultracentrifugal analysis was made with a Spinco Model E or Hitachi Model UCA-1 analytical ultracentrifugal apparatus.

The measurements of enzymatic activity were as follows: (1) ATPase activity of 
myosin $\mathrm{B}$, myosin $\mathrm{A}$ and $\mathrm{H}$-meromyosin was determined by measuring the inorganic phosphate liberated from $1 \mathrm{mM} \mathrm{ATP}$ in the presence of $1 \mathrm{mM} \mathrm{Ca}^{2+}$ at $26^{\circ} \mathrm{C}$. The components of the solvent were $0.02 \mathrm{M}$ tris- $\mathrm{HCl}$ buffer $(\mathrm{pH} 6.8)$ and 0.5 or $0.6 \mathrm{M} \mathrm{KCl}$. The inorganic phosphate $(\mathrm{Pi})$ was determined by Fiske-Subbarow's method. (2) Catalase activity was measured photometrically in $0.075 \mathrm{M}$ phosphate buffer $(\mathrm{pH} 7.0)$ at $20^{\circ} \mathrm{C}$, by a modification of Beers and Sizer's method (1952). The concentration of catalase was $1 \times 10^{-9} \mathrm{M}$ and that of $\mathrm{H}_{2} \mathrm{O}_{2}$ as a substrate was $1 \times 10^{-4} \mathrm{M}$.

The protein concentration was determined by micro-Kjeldahl and Buret methods and also spectrophotometrically at $278 \mathrm{~m} / \mu$ by the absorption value.

Freeze-thawing procedures were as follows; $4 \mathrm{ml}$ of the specimen in a glass tube $(16 \mathrm{~mm}$ in diameter) was frozen by immersion in an alcohol or iso-pentane bath cooled with dry-ice or liquid nitrogen. The specimen temperature was recorded by a thermocouple inserted in the specimen container:

Various procedures were used for controlling the freezing temperature and rate of cooling, i.e., use of double jacket, addition of dry-ice or liquid nitrogen, stepwise transfer to baths cooled to desired temperature and direct immersion in liquid nitrogen. After complete freezing at desired temperatures for $15 \mathrm{~min}$, the specimen was transferred to a bath kept at $30^{\circ} \mathrm{C}$ and thawed rapidly.

For freeze-drying, the specimen was frozen in a container of $30 \mathrm{~mm}$ in diameter and $10 \mathrm{~mm}$ of depth at given temperatures and then dried from the frozen state in a freeeze-drying apparatus with an oil diffusion pump.

\section{Results}

Myosin B. The specimen, myosin B in $0.6 \mathrm{M} \mathrm{KCl}$ and $0.02 \mathrm{M}$ tris- $\mathrm{HCl}$ buffer solution ( $\mathrm{pH}$ 6.8), was frozen in baths of $-30,-79$ and $-196^{\circ} \mathrm{C}$, and thawed at $30^{\circ} \mathrm{C}$. As shown in Table 1 , viscosity and ATPase activity were decreased by freezethawing. Neither turbidity nor precipitation was found in the thawed specimen.

Table 1. Effect of freeze-thawing on myosin B

\begin{tabular}{cccc}
\hline $\begin{array}{c}\text { Fr. Temp. } \\
{ }^{\circ} \mathrm{C}\end{array}$ & Initial & Miscosity & $\begin{array}{c}\text { ATPase activity } \\
\sim \text { Pi } / \text { min }\end{array}$ \\
\hline Control $(0)$ & 0.87 & 0.27 & 3.4 \\
-30 & 0.48 & - & 1.4 \\
-79 & 0.58 & 0.32 & 2.0 \\
-196 & 0.63 & 0.32 & 2.2 \\
\hline
\end{tabular}

Thawed at $30^{\circ} \mathrm{C}$ rapidly

The extent of denaturation of protein usually corresponds to the protein concentration. The present experiment showed that the denaturation was accelerated at the concentration was lowered, as shown in Fig. 1. For this reason, 1\% protein solutions were used as the specimens for freeze-thawing in all cases of this experiment.

In order to elucidate the relationship between denaturation and freezing condition, $4 \mathrm{ml}$ of the specimen was frozen to different temperatures at the same cooling rate 


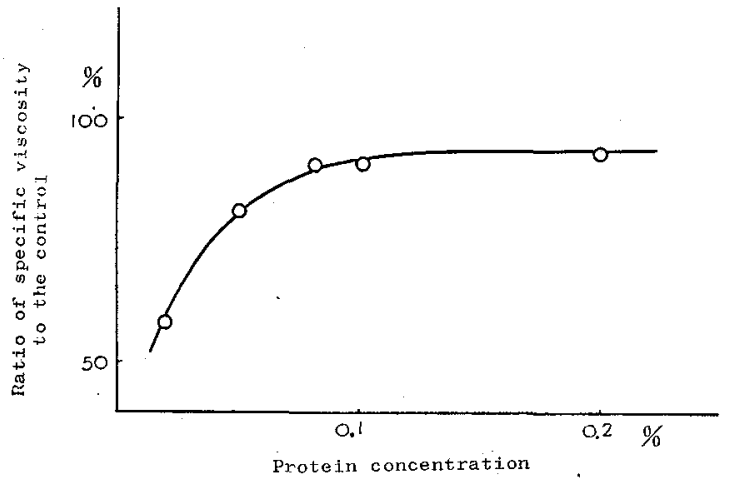

Fig. 1. Effect of the concentration of myosin B on the denaturation by freeze-thawing

Ordinate: Percentage of the specific viscosity $\left(\eta_{s p}\right)$ to the control in same concentration

Abscissa: Concentration of myosin $\mathrm{B}$ in $0.6 \mathrm{M} \mathrm{KCl}, 0.02 \mathrm{M}$ tris$\mathrm{HCl}$ buffer ( $\mathrm{pH}$ 6.8). Freezing temperature, $-30^{\circ} \mathrm{C}$

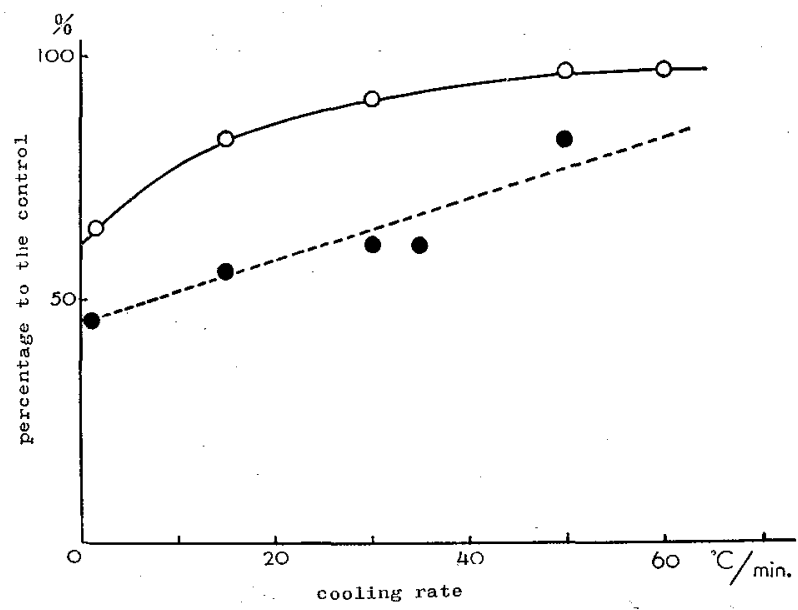

Fig. 2. Effect of cooling rate on the viscosity $\eta_{s p}(0)$ and ATPase activity (e) of myosin $\mathrm{B}$ in $0.6 \mathrm{M} \mathrm{KCl}, 0.02 \mathrm{M}$ tris- $\mathrm{HCl}$ buffer $(\mathrm{pH} 6.8)$

Ordinate: Percentage to the control. Abscissa: Cooling rate. Final freezing temperature, $-50^{\circ} \mathrm{C}$

(about $20^{\circ} \mathrm{C} / \mathrm{min}$ ) or frozen to a given temperature $\left(-50^{\circ} \mathrm{C}\right)$ at different rates of cooling. The results were shown in Figs. 2 and 3. The decrease of viscosity and ATPase activity appeared in parallel, corresponding to the freezing condition. The denaturation of the specimen increased in prominence with the lowering of the final freezing temperature at a constant cooling rate and the slowing of the rate of cooling to a given temperature. The ultracentrifugal analysis of the same materials showed no changes in sedimentation pattern and sedimentation constant as shown in Fig. 4. This suggests that there was no dissociation or association. 


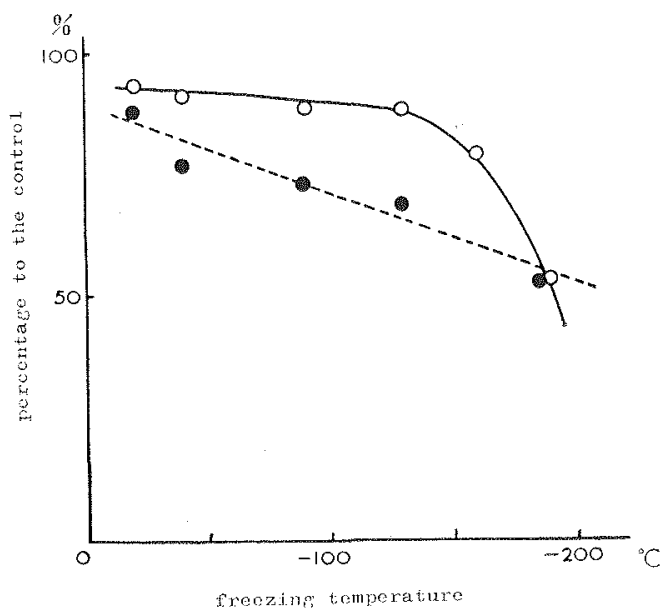

Fig. 3. Effect of freezing temperature on the viscosity $\eta_{s p}(O)$ and ATPase activity (1) of myosin $\mathrm{B}$ in $0.6 \mathrm{M} \mathrm{KCl}, 0.02 \mathrm{M}$ tris-HCl buffer ( $\mathrm{pH}$ 6.8)

Ordinate: Percentage to the control. Abscissa: Freezing temperature. Cooling rate, $20^{\circ} \mathrm{C} / \mathrm{min}$
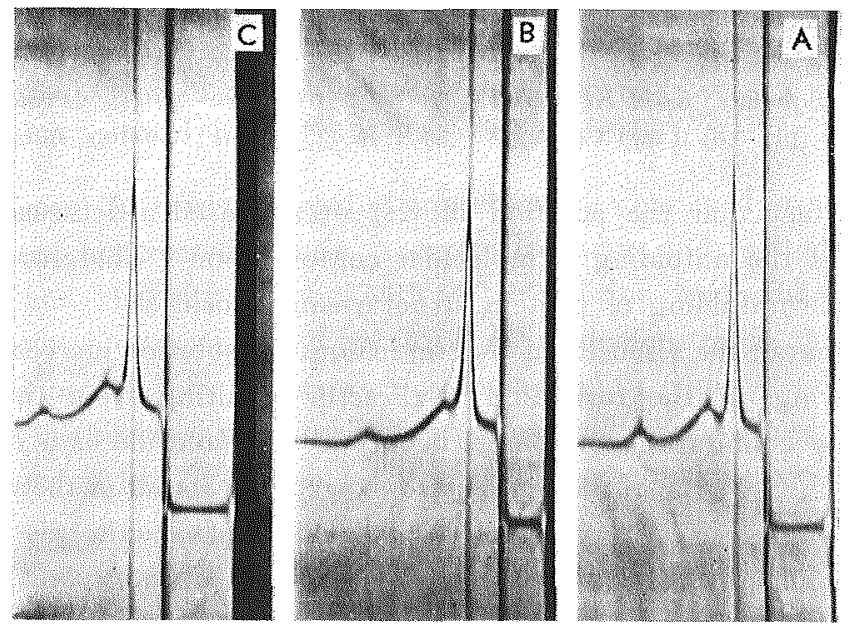

Fig. 4. Sedimentation diagrams of frozen-thawed myosin B. A, control; $\mathrm{B}$, slow freezing to $-50^{\circ} ; \mathrm{C}$, rapid freezing to $-80^{\circ} \mathrm{C}$

Protein concentration, $0.8 \%$ in $0.6 \mathrm{M} \mathrm{KCl}, 0.02 \mathrm{M}$ tris- $\mathrm{HCl}$ buffer ( $\mathrm{pH} 6.8$ ) 56100 r.p.m. 24 min after full speed was reached at $0^{\circ} \mathrm{C}$

Figure 5 shows the viscosity change occurring in the frozen-thawed specimens with time after the addition of ATP. When $1 \mathrm{mM}$ ATP was added in the presence of $1 \mathrm{~mm}$ $\mathrm{Ca}^{2+}$, the viscosity of all specimens dropped to the same value as that of the control, but its recovery rate was slower than the control. This suggests that the actin-myosin binding site of myosin B probably sustains no damage by freeze-thawing. The decrease of recovery rate of viscosity is related to the decrease of ATPase activity.

The decrease of viscosity by freezing suggests some change in the configuration of 


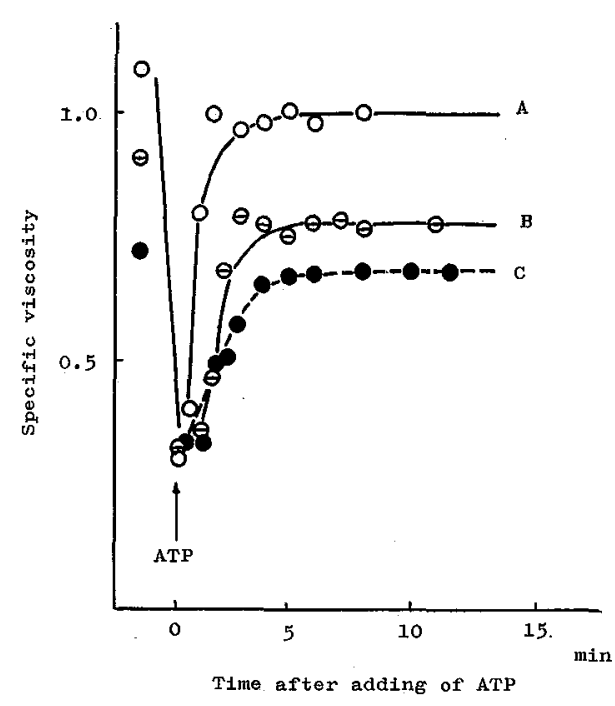

Fig. 5. Time course of viscosity change by adding of ATP on frozen-thawed myosin B Ordinate: Specific viscosity. Abscissa: Time after adding of $1 \mathrm{mM} \mathrm{ATP}$ at $26^{\circ} \mathrm{C}$.

$\bigcirc$, control; $\oplus$, cooling rate $15^{\circ} \mathrm{C} / \mathrm{min}$; - $1^{\circ} \mathrm{C} / \mathrm{min}$. Solvent: $0.6 \mathrm{M} \mathrm{KCl}, 0.02 \mathrm{M}$ tris- $\mathrm{HCl}$ buffer $(\mathrm{pH} 6.8), 1 \mathrm{mM} \mathrm{Ca}{ }^{2}+$

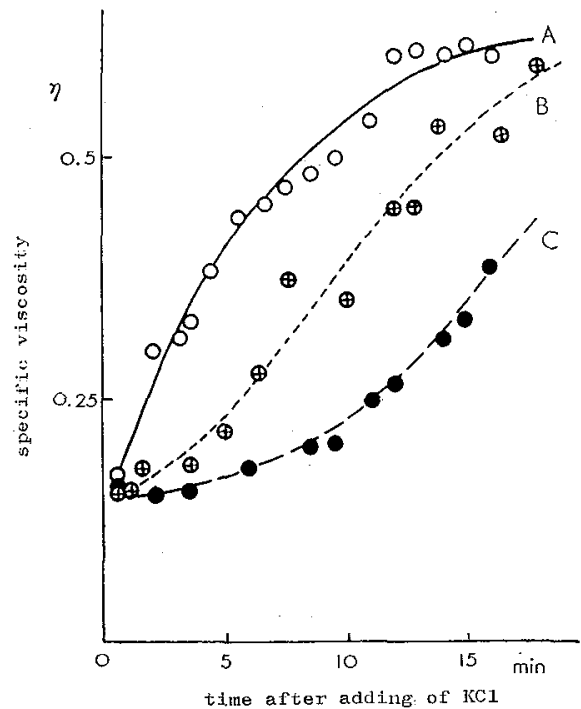

Fig. 6. Effect of freeze-thawing on the polymerization of $\mathrm{G}$-actin

Ordinate: Specific viscosity

Abscissa: Time after adding of $\mathrm{KCl}$

$O$, control; $\oplus$, frozen to $-50^{\circ} \mathrm{C}$; frozen to $-170^{\circ} \mathrm{C}$. Protein concentration, $2.5 \mathrm{mg} / \mathrm{ml}$. Cooling rate, $50^{\circ} \mathrm{C} / \mathrm{min}$

myosin B. The fact that the addition of $8 \mathrm{M}$ urea caused a decrease of viscosity in myosin $\mathrm{B}$ indicates the unfolding of molecular conformation. Therefore, freeze-thawing may also cause the unfolding of protein structure in myosin $\mathrm{B}$.

Actin. In general, the viscosity of G-actin in aqueous solution increased by an addition of $0.1 \mathrm{M} \mathrm{KCl}$, owing to the formation of $\mathrm{F}$-actin resulting from the polymerization of G-actin. If any configurational change occurs in the molecule as a result of freezing, a certain change in G-F transformation is also expected as found in the case of enzymatic activity. As shown in Fig. 6, the rate of polymerization of G-actin was less in specimens frozen at lower temperatures, but the final value of the viscosity was almost the same as that of the control. Thus, with freezing, the intrinsic viscosity decreased in F-actin, but not in G-actin. In both G- and F-actin, neither dissociation nor association was found.

These results suggest the occurrence of a certain configurational change in $F$-actin and a slight change at the binding site of G-actin.

Synthetic actomyosin. As mentioned above, the decrease of viscosity in myosin B by an addition of ATP is not affected by freezing. In myosin B, the binding sites of actin and myosin $\mathrm{A}$ are masked by the binding of both proteins. If actin and myosin A are separated, each of their binding sites may be exposed to the solvent. Therefore, a certain change in such exposed binding sites, resulting from freeze-thawing, may also cause a change in the binding ability of actin and myosin. From this point of view, the effect of freeze-thawing on the binding sites of both proteins was examined. 


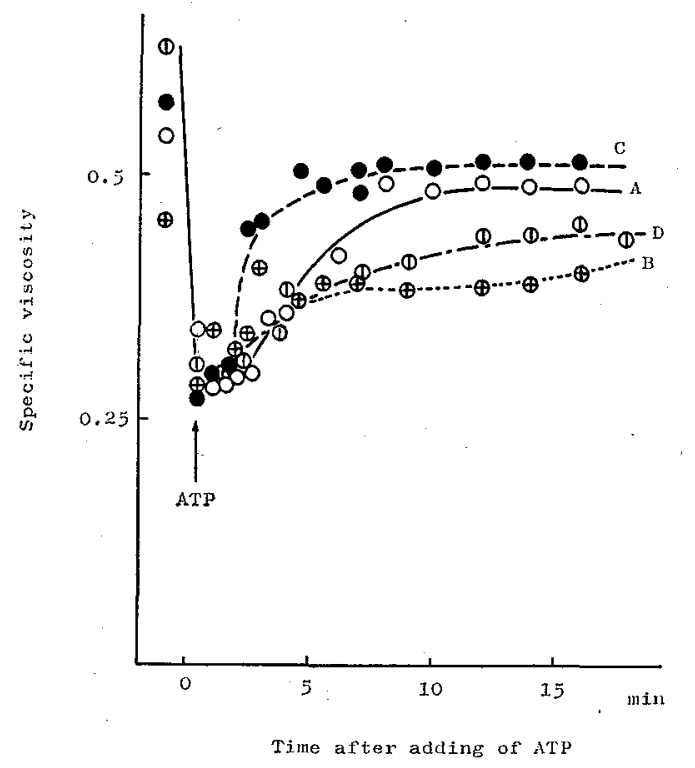

Fig. 7. Time course of viscosity change by adding of ATP on frozen-thawed synthetic actomyosin

Ordinate: Specific viscosity. Abscissa: Time after adding of $1 \mathrm{mM}$ ATP at $26^{\circ} \mathrm{C}$

O, control (A.M.); $\oplus$, A.M*.; $^{*}, A^{*} . M . ;(1), A^{*} . M^{*}$. A., actin; M., myosin B.

Solvent: $0.6 \mathrm{M} \mathrm{KCl}, 0.02 \mathrm{M}$ tris- $\mathrm{HCl}$ buffer $(\mathrm{pH} 6.8), 1 \mathrm{mM} \mathrm{Ca}^{2+}$.

* shows frozen-thawed specimen. Final freezing temperature, $-170^{\circ} \mathrm{C}$

Actin and myosin A, frozen-thawed separately, were combined in such combinations, as treated actin and nontreated myosin $\mathrm{A}$ or treated actin and treated myosin $\mathrm{A}$. The ATPase activity and viscosity change with ATP addition were then measured. The viscosity of myosin A increased by freezing. This demonstrates the typical mode of unfolding of protein molecule. In synthetic actomyosin, a complex of the treated actin and myosin, used in this case, viscosity decreased markedly but ATPase activity decreased slightly. As shown in Fig. 7, viscosity of the synthetic actomyosin, of which each component was treated, decreased to the same value as the control by an addition of ATP and finally recovered to their original values. In these specimens, there was a slight difference in the rate of recovery, in parallel with the ATPase activity.

These results suggest that the binding sites of actin and myosin A sustain hardly any damage by freezing, despite their exposed state.

Myosin A. The results obtained in myosin B showed an appearance of the unfolding of the protein molecule by freeze-thawing. In order to confirm this, several physical measurements were made on the freeze-thawed myosin A, instead of myosin B. Myosin $B$ is inadequate for these measurements, as it is too opaque.

In rapid freezing, myosin $A$ showed no changes in rotatory parameters $-b_{0}$ and $-a_{0}$, representing the helix contents of protein molecule. This agrees with the results obtained in myosin B. On the contrary, these parameters altered in correspondence to the freezing temperature at a slow rate of cooling. Experimental results, in which helix parameters, viscosity, difference spectrum and enzymatic activity were measured, are shown 
in Figs. 8 and 9 . The decrease of $-b_{0}$, the increase of $-a_{0}$ and the increase of viscosity show typical patterns of transconformation in protein molecules. This indicates the unfolding of the helix in the protein molecules, similar to that found in the denaturation with physical or chemical agents. From the fact that $-b_{0}$ of myosin A decreased from 330 to 260 in the freezing down to $-196^{\circ} \mathrm{C}$, it can be estimated that

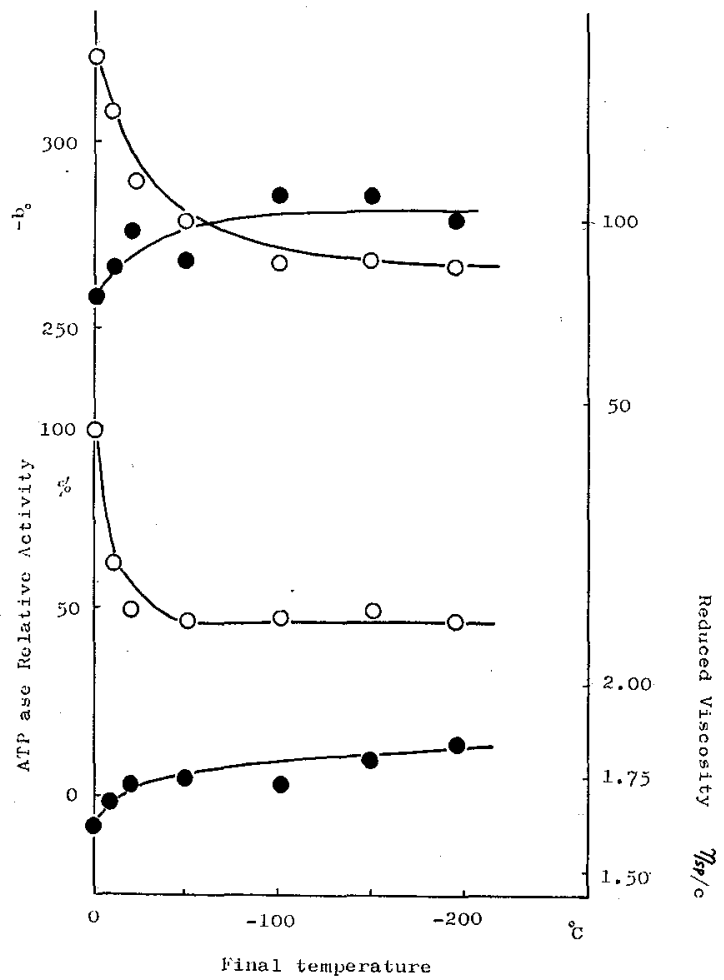

Fig. 8. Effect of freezing temperature on the conformational parameters of frozen-thawed myosin $\mathrm{A}$

Upper: $O,-b_{0} ; \bullet,-a_{0}$

Lower: 0 , ATPase activity; $\bullet$. reduced viscosity $\eta_{s p} / \mathrm{c}$

Solvent, $0.5 \mathrm{M} \mathrm{KCl}, 0.02 \mathrm{M}$ tris- $\mathrm{HCl}$ buffer $(\mathrm{pH} 6.9$ )
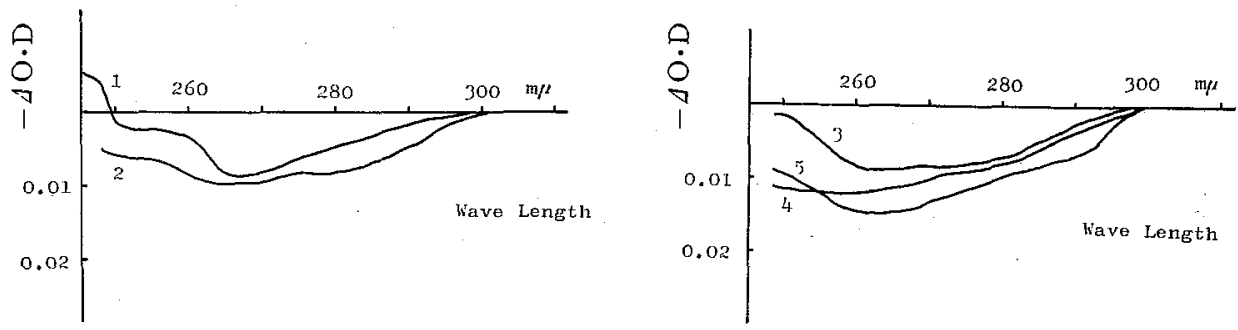

Fig. 9. Difference spectrum of frozen-thawed myosin A

Protein concentration: $0.1 \%$ in $0.5 \mathrm{M} \mathrm{KCl}, 0.02 \mathrm{M}$ tris- $\mathrm{HCl}$ buffer $(\mathrm{pH} 6.9)$ Reference: Native specimen in same concentration. Freezing temperature: (1),$-10^{\circ} \mathrm{C} ;(2),-50^{\circ} \mathrm{C} ;(3),-100^{\circ} \mathrm{C} ;(4),-150^{\circ} \mathrm{C} ;(5),-196^{\circ} \mathrm{C}$ 
$25 \%$ of the helix is unfolded with freezing. This value is not so high as those estimated in the materials unfolded by other agents.

In general, the difference spectrum indicates the shift of the absorption band in the region of a certain wave length. The shift to the shorter wave length is called a blue shift and it has a negative value in $\Delta \mathrm{O} \cdot \mathrm{D}$. As shown in Fig. 9, frozen specimens showed a small blue shift in the region between $260 \mathrm{~m} \mu$ and $280 \mathrm{~m} \mu$. This result shows the occurrence of some changes in the behavior of hydrophobic chromophores, such as tryptophan or tyrosine residues, caused by transfer from "burried state" to "exposed state" in the solvent atmosphere. In other words, this indicates the transconformation of protein molecule resulting from the unfolding of helical structure. The values of $-\Delta \mathrm{O} \cdot \mathrm{D}_{290}$ increased as the freezing temperature decreased. Such a trend is similar to that found in rotatory dispersion or viscosity, as mentioned above.

Ultracentrifugal analysis indicated that no dissociation or association in protein molecules occurred.

From these results; it is concluded that the helical structure of myosin A is partially destroyed by freeze-thawing depending upon the freezing temperature.

Meromyosin. The viscosity of G-actin is not affected by freeze-thawing, although a transconformation of molecule occurs in F-actin and myosin. This fact suggests some relationship between the shape of protein molecule and the stability of the protein against freeze-thawing.

Myosin $\mathrm{A}$ is dissociated by trypsin digestion into two subunits of $\mathrm{H}_{-}$and L-meromyosin.

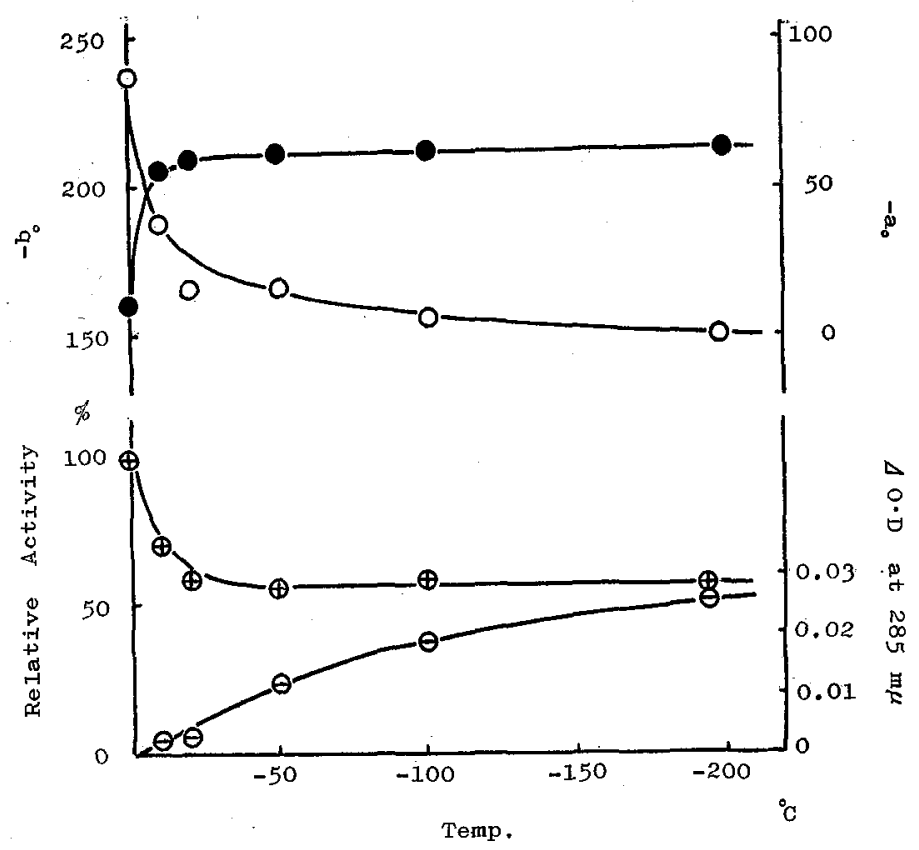

Fig. 10. Effect of freezing temperature on the conformational parameters of frozen-thawed H-meromyosin $\mathrm{O},-b_{0} ; \bullet,-a_{0} ; \oplus$, ATPase activity $\ominus,-\Delta \mathrm{O} \cdot \mathrm{D}_{285}$ Solvent: $0.02 \mathrm{M}$ tris- $\mathrm{HCl}$ buffer $(\mathrm{pH} 6.8)$ 


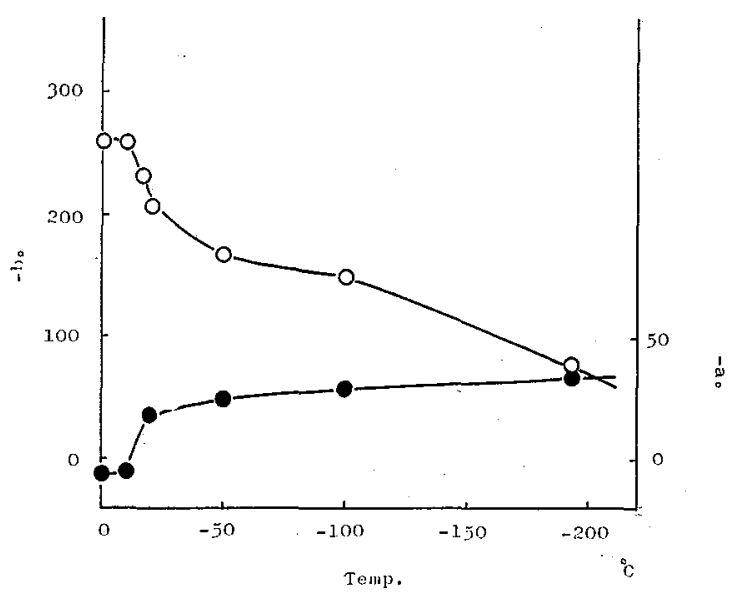

Fig. 11. Effect of freezing temperature on the helix parameters of frozen-thawed L-meromyosin

O. $-b_{0} ; \bullet,-a_{0}$. Solvent : $0.5 \mathrm{M} \mathrm{KCl}, 0.02 \mathrm{M}$ tris- $\mathrm{HCl}$ buffer $(\mathrm{pH} 6.8$ )
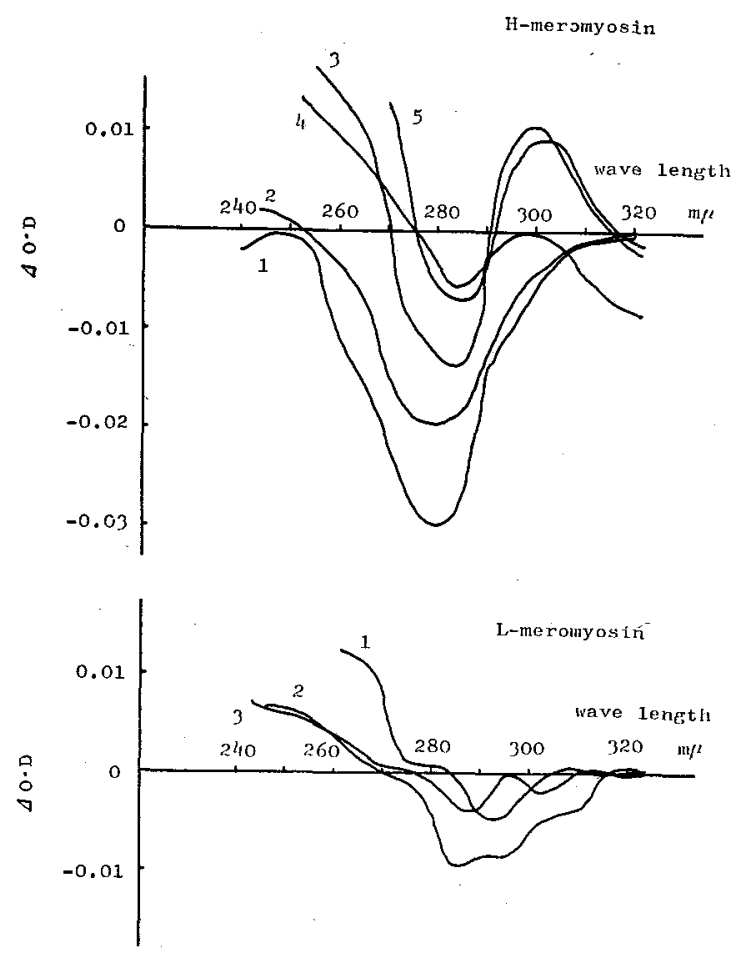

Fig. 12. Difference spectrum of frozen-thawed $H$ - and L-meromyosin Upper: H-meromyosin. Freezing temperature: (1), $-196^{\circ} \mathrm{C} ;(2),-100^{\circ} \mathrm{C}$; (3), $-50^{\circ} \mathrm{C} ;(4),-20^{\circ} \mathrm{C} ;(5),-10^{\circ} \mathrm{C}$

Protein concentration : $0.1 \%$ in $0.02 \mathrm{M}$ tris- $\mathrm{HCl}$ buffer ( $\mathrm{pH} 6.8$ )

Reference: Native specimen

Lower: L-meromyosin. Freezing temperature : (1), $-20^{\circ} \mathrm{C} ;(2),-50^{\circ} \mathrm{C} ;(3),-196^{\circ} \mathrm{C}$ Protein concentration: $0.1 \%$ in $0.5 \mathrm{M} \mathrm{KCl}, 0.02 \mathrm{M}$ tris- $\mathrm{HCl}$ buffer $(\mathrm{pH} 6.8$ ) Reference: Native specimen 
H-meromyosin has a rather globular type but L-meromyosin is a typical rod-like protein. If there is some difference in changes in the molecular conformation of different shapes of proteins, even drived from the same origin, a comparison of such differences may be useful for the explanation of the mechanism of freezing injury.

$\mathrm{H}$-meromyosin of $0.8 \%$ in $0.02 \mathrm{M}$ tris- $\mathrm{HCl}$ buffer $(\mathrm{pH} 6.8)$ and $0.8 \%$ L-meromyosin in $0.02 \mathrm{M}$ tris- $\mathrm{HCl}$ and $0.5 \mathrm{M} \mathrm{KCl}(\mathrm{pH}$ 6.8) were frozen-thawed and measured on the physicochemical parameters. As shown in Figs. 10-12, changes in the value of $-b_{0}$ and $-a_{0}$, viscosity, $-\Delta \mathrm{O} \cdot \mathrm{D}_{285}$ and enzymatic activity in both proteins almost correspond to the freezing temperature. In a comparison of freezing at $-196^{\circ} \mathrm{C}$, however, $-b_{0}$ value decreased from 240 to 150 in H-meromyosin and from 250 to 80 in L-meromyosin. This means the unfolding of $70 \%$ of the helix in the latter in contrast to the mere $27 \%$ in the former.

As shown in Fig. 12, the value of $-\Delta \mathrm{O} \cdot \mathrm{D}_{285}$ of $\mathrm{H}$-meromyosin was greater than that of L-meromyosin in the same protein concentration. If it indicates the difference in conformational change, this is opposite to that obtained in rotatory dispersion. Such a discrepancy may be caused by some difference in the over-all configuration of both proteins, as will be discussed later. The data obtained in rotatory dispersion represent the difference in transconformation of both proteins.

Catalase. Catalase is a typical globular protein composed of four subunits. It was reported by some investigators (Ogawa, 1953; Shikama, 1961, 1963) that the enzymatic activity of catalase was reduced by freeze-thawing.

It has not yet been clarified as to whether or not a conformational change of catalase occurs with freezing. As described before, the experiments on actin and meromyosin suggest that the conformational change due to freeze-thawing has some correlation with the over-all configuration of the protein molecule. Catalase, a typical globular protein,

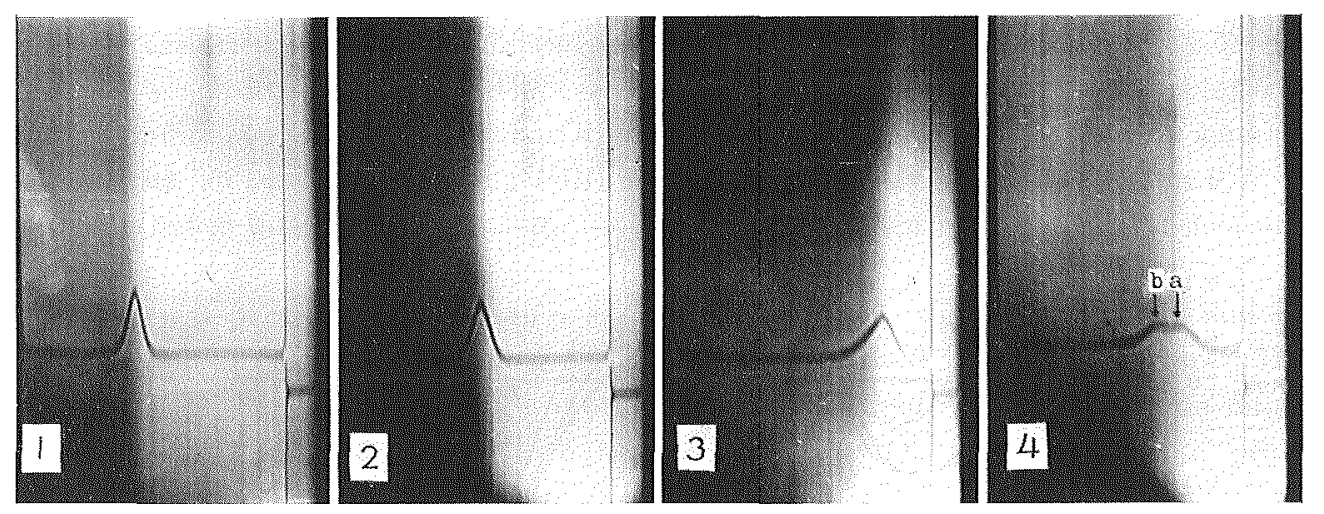

Fig. 13. Sedimentation diagrams of frozen-thawed and freeze-dried catalase

1 Native. 57 min after full speed reached. $S_{20, w}=11.5$

2 Freeze-thawing. Freezing temp. $-60^{\circ} \mathrm{C}, 46 \mathrm{~min} . \mathrm{S}_{20, \mathrm{w}}=12.4$

3 Freeze-drying. Freezing temp. $-40^{\circ} \mathrm{C} .50 \mathrm{~min} . \mathrm{S}_{20, \mathrm{w}}=3.8$

4 Freeze-drying. Freezing temp. $-60^{\circ} \mathrm{C}, 59 \mathrm{~min}$.

a: $\mathrm{S}_{20, \mathrm{w}}=4.3 ; \mathrm{b}: \mathrm{S}_{20, \mathrm{w}}=6.2$

Protein concentration, $0.42 \%$; Solvent, $0.075 \mathrm{M}$ phosphate buffer (pH 7.0); 55430 r.p.m.; $20^{\circ} \mathrm{C}$ 
also may not give rise to transconformation with freezing, even though the enzymatic activity is decreased.

In order to define this point, difference spectrum in the ultraviolet region and Soret band at $405 \mathrm{~m} \mu$, viscosity, sedimentation and enzymatic activity were measured on the frozen-thawed catalase. For globular protein, the shift in the absorption band generally indicates a change in the molecular conformation of protein. In catalase, the spectral shift at the ultraviolet wave length and Soret band indicates some changes in molecular conformation of protein and in haem group as an active site, respectively.

The difference spectrum of the slowly frozen catalase is illustrated in Fig. 14. A very slight shift was observed in both regions of around $280 \mathrm{~m} \mu$ and $405 \mathrm{~m} \mu$. Although there was no change in the viscosity, the enzymatic activity decreased as the freezing temperature was lowered, as found in myosin. The data are shown in Figs. 13 and 17.
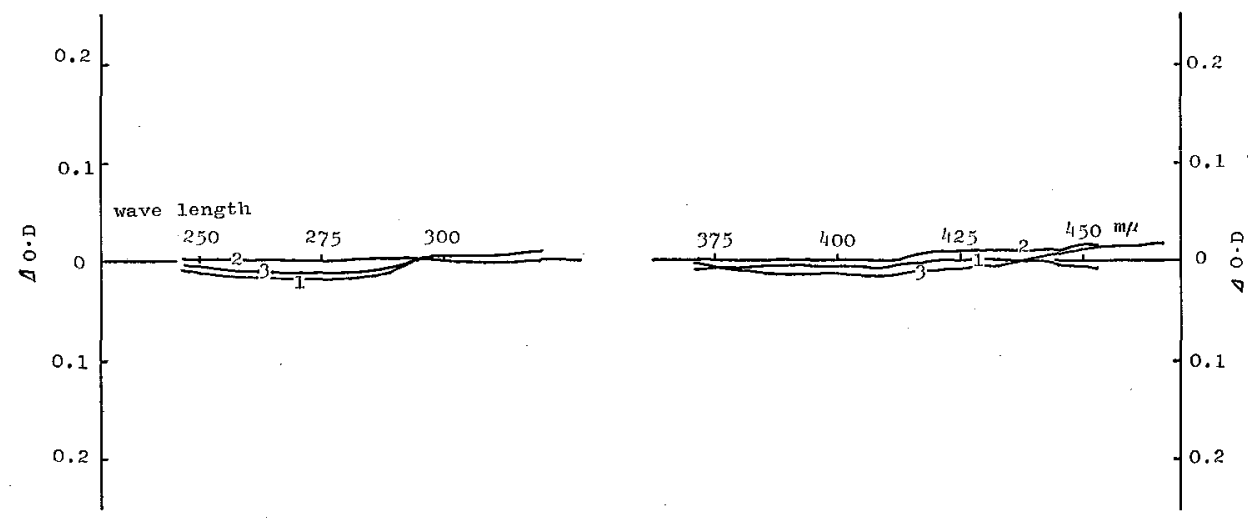

Fig. 14. Difference spectrum of frozen-thawed catalase Protein conc., $0.14 \%$; Solvent, $0.075 \mathrm{M}$ phosphate buffer $\mathrm{pH} 7.0$ Reference: Native specimen

Freezing temperature: (1), $-20^{\circ} \mathrm{C} ;(2),-80^{\circ} \mathrm{C} ;(3),-196^{\circ} \mathrm{C}$
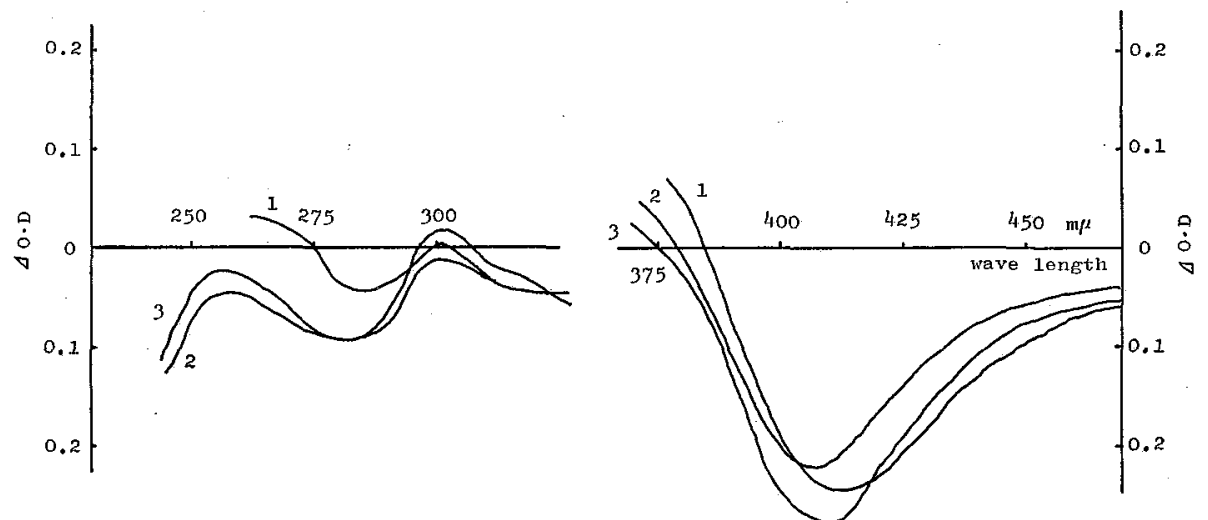

Fig. 15. Difference spectrum of freeze-dried catalase (DI) Protein conc., $0.14 \%$; Solvent, $0.075 \mathrm{M}$ phosphate buffer $\mathrm{pH} 7.0$ Reference: Native specimen

Freezing temperature: (1), $-20^{\circ} \mathrm{C} ;(2),-80^{\circ} \mathrm{C} ;(3),-196^{\circ} \mathrm{C}$ 

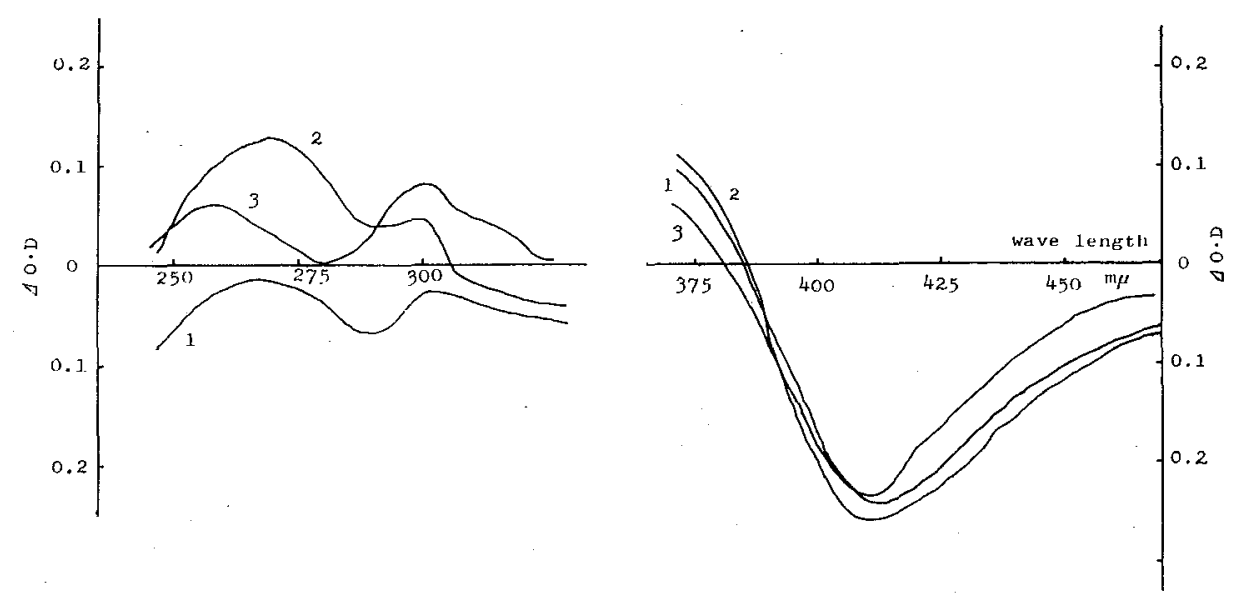

Fig. 16. Difference spectrum of freeze-dried catalase (DII)

Protein conc., $0.14 \%$; Solvent, $0.075 \mathrm{M}$ phosphate buffer $\mathrm{pH} 7.0$

Reference: Native specimen

Freezing temperature: (1), $-20^{\circ} \mathrm{C} ;(2),-80^{\circ} \mathrm{C} ;(3),-196^{\circ} \mathrm{C}$

The sedimentation pattern and sedimentation constant showed no dissociation or association, as shown in Figs. 13 and 17.

From these results, it is concluded that, in catalase, freeze-thawing reduces the enzymatic activity, but does not initiate the conformational change on catalase:

Freeze-dried catalase. According to Tanford (1962), the freeze-dried catalase was dissosiated to subunits and lost its enzymatic activity. The correlation between such changes and the freeze-drying conditions has not become evident as yet.

The same measurements as used in the frozen-thawed catalase were also carried out on the freeze-dried catalase. Catalase of $3 \%$ in $0.075 \mathrm{M}$ phosphate buffer $(\mathrm{pH} 7.0$ ) in a container was frozen at a given temperature and dried for about 5 hours by using only a rotary pump (conventionally named DI). Some of them were further dried for another 5 hours with an oil diffusion pump (DII). After drying, they were resolved in $0.075 \mathrm{M}$ phosphate buffer ( $\mathrm{pH} 7.0$ ) to a concentration of $0.5 \%$, and then used for several measurements.

Difference spectra of those materials, DI and DII, were shown in Figs. 15 and 16. In the region of the Soret band, great peaks were observed in both specimens. The values of peak height, $-\Delta \mathrm{O} \cdot \mathrm{D}_{405}$, were negative and showed no dependency on either the freezing temperature or the extent of dehydration (DI and DII). These peaks indicate the reduction in absorption of the haem group at $405 \mathrm{~m} \mu$, but not the shift of the absorption band, because the peak of the haem group remains at $405 \mathrm{~m} \mu$ even in difference spectrum.

Ultracentrifugal analysis proved that the freeze-dried catalase was dissociated into $3.7 \mathrm{~S}$ subunits of monomer, except for few cases. Such dissociation was independent of the freezing or drying conditions, as shown in Figs. 13 and 17.

The enzymatic activity was extremely reduced in the drying DI and a little further in the drying DII. It also depended upon the freezing temperature. 

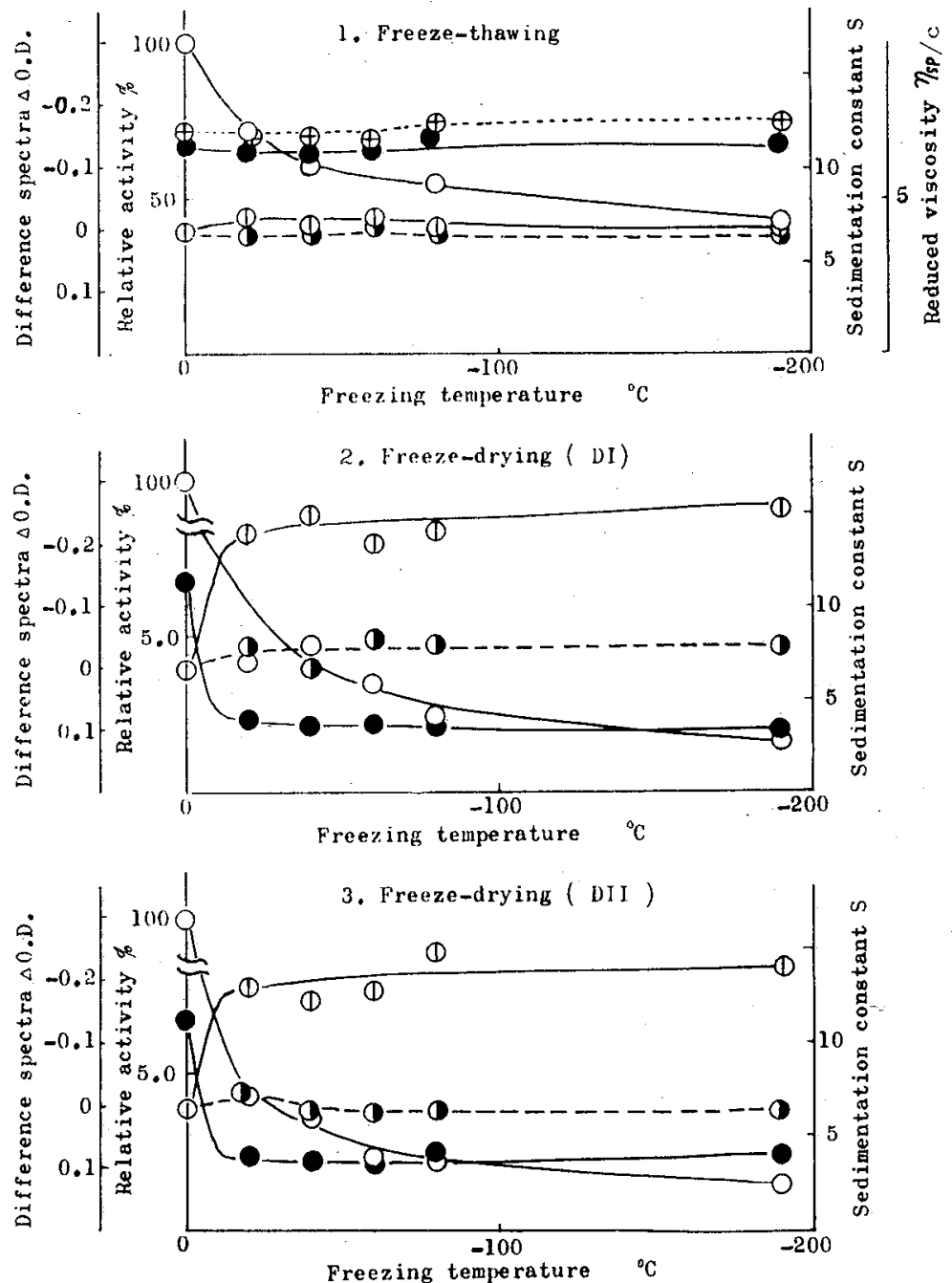

Fig. 17. Changes in the conformational parameters and enzymatic activity of frozen-thawed and freeze-dried catalase

$\bigcirc$, enzymatic activity; $\oplus$, reduced viscosity $\eta_{s p} / \mathrm{c} ; \bullet$, sedimentation constant $\mathrm{S} ; \Theta, \Delta \mathrm{O} \cdot \mathrm{D}_{405} ; \mathrm{O}, \Delta \mathrm{O} \cdot \mathrm{D}_{278}$

In the region of around $280 \mathrm{~m} \mu$ of the difference spectrum, a blue shift was observed in some cases, but a red shift was observed in other cases. The shift around $280 \mathrm{~m} \mu$ is independent of the freezing or drying conditions. Whether or not the conformation of dissociated subunits differs from that of native protein is still obscure.

The reduction of absorption at the Soret band probably indicates the alteration of the state of haem group caused by dissociation. The reduction of enzymatic activity may have resulted from such a change.

\section{Discussion}

Most of the studies on denaturation due to freeze-thawing are concerned solely with 
enzymatic activity and very few studies have been done on the conformational change of protein. The present experiment showed that freeze-thawing causes the partial unfolding of the helical structure in a fibrous protein, namely, a conformational change of the protein. Both of the changes in molecular structure and enzymatic activity occur depending on the rate of cooling and the freezing temperature. The conformational change with freezing is not so remarkable as that with urea or other chemical agents : the helix of myosin $\mathrm{A}$ is almost completely disrupted with $8 \mathrm{M}$ urea, but only one-fourth of the helix is unfolded by freezing at $-196^{\circ} \mathrm{C}$. It was also demonstrated in this experiment that, in catalase, the enzymatic activity decreases depending upon the freezing temperature, but no changes appear in the molecular conformation.

From the evidence that the denaturation due to freezing depends upon the freezing conditions, it is considered that the phase change of solvent water with freezing may play some role in the mechanism of denaturation.

The mechanical damage by ice crystal formation and injury by concentrated salts have long been regarded as the two main causes of freezing injuries occurring in various kinds of biological materials. However, it is unlikely that ice crystals cause mechanical damage to the protein molecule, because of a spaceful structure of water and ice (Bernal, 1965) and also the large size of ice crystals in comparison to the protein molecule. The following evidences also lessen the possibility of denaturation by salt concentration. For instance, myosin is usually exposed to highly concentrated $\mathrm{KCl}$ during its preparation procedure. Tonomura (1962) reported that the conformational change of myosin caused by exposing to concentrated $\mathrm{KCl}$ is reversible. The freezing temperatures, used in all cases in this experiment, were below the eutectic points of the solvents.

The dependency of the denaturation on the freezing conditions suggests some interaction between the hydration shell of the protein and surrounding ice crystals in the solvent. A hypothesis along this line was presented by Shikama (1963). He examined the denaturation of myosin and catalase with freezing by measuring enzymatic activity and obtained the result that the activity was completely reduced by freezing in a range between -20 and $-80^{\circ} \mathrm{C}$. He assumed some interaction between ice crystal (hexagonal type) in the solvent and an iceberg structure of the hydration shell (cubic type) of the protein. In opposition to his results, however, such a critical temperature range was not obtained in the present experiment, in which all changes occurred in parallel with the freezing temperature. This incoincidence probably comes from the difference in the experimental conditions: As a fairly large amount of highly concentrated protein was used, the rate of cooling in the present experiment was assumed to be lower than that in Shikama's. Accordingly, the transition of crystal form of ice can not be expected in this experiment.

In recent years, many investigators have reported on the contribution of water to the structure of biopolymers (Klotz, 1962, 1964; Némethy and Scheraga, 1962; Tanford, 1962). As well known, protein and nucleic acid have hydration water oriented around the polar or non-polar groups in the molecule. The polar groups attract water molecule by electrostatic forces, and non-polar or hydrophobic groups form the clathlate structure of protein (iceberg structure). The latter is very important to the formation of hydrophobic bonds for maintaining the ordered structure of protein. According to 
Bernal (1965), the structure of an iceberg has a regular arrangement of water molecules, different from liquid water, but the arrangement is not so regular when compared to pure ice crystals.

The following assumption will be made from the freezing process of the protein solution: ice crystals grow gradually and contact with the hydration shell of polar or non-polar groups in the protein molecule during freezing.

In this process, the ice crystals reveal an interaction with the hydration shell; such as the formation of new hydrogen bonds between them, and subsequently the state of hydration shell will be disturbed. As the hydrogen bonds of water, ice, hydration shell or protein molecule are of a co-operative nature (Bernal, 1965), the disturbance propagates to internal hydrogen bonds in the protein molecule and also affects the hydrophobic bonds.

Ultracentrifugal analysis, demonstrating no occurrence of dissociation and association, suggests that the weak bonding such as the hydrogen bonds or hydrophobic bonds are affected by freezing.

Myosin is a rod-shape protein, which consists of a helical structure and internal hydration water in the helix contributing to maintain the protein conformation (SzentGyörgyi, 1955). This molecular structure is recognized to be very unstable and easily affected by the disturbance of the hydration shell.

Generally speaking, on the contrary, the hydrogen bond becomes stable as the temperature is lowered. Such a discrepancy can hardly be explained. As assumption, that the disturbance may occur during the freezing process, is not recognizable owing to the dependency of denaturation on the freezing conditions. The main dominant disturbance probably appears during the freezing process.

The denaturation of myosin depended on the following two factors in freezing: one was the rate of cooling at a given temperature and the other was the final freezing temperature at a constant rate of cooling. From the supposition mentioned above, it might be considered that the dependency on the rate of cooling is concerned with the mode of the disturbance and the dependency on the freezing temperature is concerned with the amount of disturbed hydration water. In other words, the lower the freezing temperature, the more the hydration shell is disturbed, and the slower the rate of cooling, the more the disturbance becomes localized or uneven.

The comparison between fibrous and globular protein is also an important problem in this experiment. As described before, helix contents decreased remarkably in L-meromyosin, fibrous protein, but slightly in H-meromyosin, globular-like protein. G-actin and catalase, both typical globular proteins, did not change their conformation. In these globular proteins, it is assumed that since the area to be exposed to the solvent water is small and water molecules can not penetrate into the protein molecule, the disturbance of hydration shell will be less than that of fibrous proteins.

A few studies were done on the temperature dependency of the protein denaturation in freezing. In the experiment carried out on chromoprotein of phycoerythrium, the optical density at visible wave length decreased on the freezing temperature (Leibo and Jones, 1964). This suggests the conformational change depending on the freezing temperature. For lactic dehydrogenase, an exchange of subunits occurred during the freezing process, and the rate of hybrid formation was reduced in rapid freezing and thawing 
(Kaplan, 1964).

Concerning the globular proteins, catalase activity and the rate of polymerization of G-actin decreased depending on the freezing temperature without any conformational change. Those results might indicate that the local disturbance occurred around the active site, which had been exposed to solvent water, and brought about a decrease of enzymatic activity or polymerization rate without a conformational change of the whole molecule. The appearance of very slight shift at $405 \mathrm{~m} \mu$ and $278 \mathrm{~m} \mu$ in difference spectrum of the frozen-thawed catalase indicates such a local change.

Myosin-ATPase activity has some relation with the secondary or tertiary structure of protein. Connell (1960) reported that the SH content of fish myosin did not change during storage in the frozen state, although its activity and viscosity were reduced. The decrease of ATPase activity of myosin may have resulted from the change in the molecular conformation.

Spectral shifts of the frozen-thawed myosin A and L-meromyosin were not so identical as those of H-meromyosin, in spite of the remarkable decrease of helix contents as observed in rotatory dispersion. This can be explained as follows: since most chromophores in the rod-type protein are exposed to the solvent atmosphere in the native state, no changes appear in the interaction between the chromophores and the solvent, even after the conformational change of the protein, in contrast to the globular protein.

Tanford (1962) reported that the freeze-dried catalase was dissociated into monomer, dimer and other mixtures of subunits. In the present experiment, a dissociation only to $3.7 \mathrm{~S}$ subunit of monomer occurred, except in a few cases, but it had not relationship with the extent of dehydration. The essential nature of the bonding among those subunits has not yet become evident, and subsequently, the mechanism of dissociation by drying is still obscure. Litt (1958) observed that haemocyanin was denatured by freeze-drying, but not by freeze-thawing. It is conjectured that protein, such as catalase or haemocyanin, which is composed of subunits containing metal, is unstable to complete dehydration. However, most of the globular proteins, such as lysozyme and G-actin, are known to be stable against freeze-drying. This suggests some role of water in the binding of subunits.

In order to advance a further discussion, it is necessary to identify the physical nature of water and ice and the interaetion between the hydration water and the solvent water in the polymer solution during the freezing process.

\section{Acknowledgments}

The author wishes to thank Professor Tokio Nei, of the Institute of Low Temperature Science, Hokkaido University, for his interest and encouragement.

$\mathrm{He}$ is also grateful to Professor Toshizo Isemura and Assistant Professor Kōzō Hamaguchi, the Institute for Protein Research, Osaka University, for their kind guidance and encouragement.

A part of this work was done at the Institute for Protein Research.

\section{References}

BEERs, R. and SIZER, I. M. 1952 A spectrophotometric method for measuring the breakdown of 
hydrogen peroxide by catalase. J. Biol. Chem., 195, 133-140.

BERNAL, J. D. 1965 The structure of water and its biological implications. In The State and Movement of Water in Living Organisms (G. E. FoGG, ed.), Cambridge Univ. Press, London, $17-32$.

CONNELL, J. J. 1960 Changes in the adenosintriphosphatase activity and sulphydryl groups of cod flesh during frozen storage. J. Sci. Food Agric., 11, 245-249.

Connelt, J. J. 1960 Changes in the actin of cod flesh during storage at $-14^{\circ}$. J. Sci. Food Agric., 11, 515-519.

Hanafusa, N. 1962 Denaturation of myosin B due to freezing and thawing. Low Temp. Sci., B 22, 119-131.*

HANAFUSA, N. 1964 Denaturation of myosin A resulting from freezethawing. Low Temp. Sci., B 22, 81-94.*

KAPLAN, N. O. 1964 Lactic dehydrogenase: Structure and function. In Subunit Structure of Protein. Brookhaeven Natl. Lab., Upton, New York, 131-153.

KLotz, I. M. 1962 Water. In Horizon in Biology (M. KASHA and B. PULLMAN, eds.), Brookhaeven Natl. Lab.; Upton, New York, 532-550.

KLOTZ, I. M. 1964. Role of. water structure in macromolecule. Fed. Proc., 24, Suppl. 15, S-24-33:

LEIBO, S. P. and JONES, R. 1964 Freezing of the chormoprotein phycoerythrium from the red alga Porphyridium. Arch. Biochem. Biophys., 106, 78-88.

LITT, M. 1958 Preservation of haemocyanin. Nature, 181, 1075.

MARKERT, C. L. 1963 Lactic dehydrogenase isozyme: Dissociation and recombination of subunit. Science, 140, 1329-1330.

Moffit, W. and YANG, J. T. 1956 The optical rotatory dispersion of simple polypeptide. Proc. Natl. Acad. Sci., 42, 596-605.

OGAWA, T. 1953 Effect of low temperature on yeast catalase. Low Temp. Sci, 10, 175-199.*

NÉmETHY, G. and ScherAGA, H. A. 1962 The structure of water and hydrophobic binding in protein. J. Phys. Chem., 66, 1773-1789.

SzENT-GyörgYI, A. G. 1955 Bioenergitics. Acad. Press Inc., New York, 143 pp.

SHIKAMA, K. and YAMAZAKI, I. 1961 Denaturation of catalase by freezing and thawing. Nature, 190, 83-84.

ShIKAMA, K. 1963 Denaturation of catalase and myosin by freezing and thawing. Sci. Rep. Tohoku Univ., Biol. 29, 91-106.

TANFORD, C. 1962 Contribution of hydrophobic interaction to the stability of the globular conformation of protein. J. Amer. Chem. Soc., 84, 4220-4247.

TANFORD, C. and LAVRien, R. 1962 Dissociation of catalase into subunit. J. Amer. Chem. Soc., 84, 1892-1896.

TONOMURA, Y., SEKIYA, K. and IMAMURA, K. 1962 The optical rotatory dispersion of myosin A. I. Effect of inorganic salts. J. Biol. Chem., 237, 3110-3115.

* In Japanese with English Summary. 